(C) Dereito Vol.29, n01:175-178 (Xaneiro-Xuño, 2020) • ISSN 1132-9947

\title{
GARCÍA RUBIo, María Paz (dir.); AMMERMAN YEBRA, Julia (coord.); GARCÍA GOLDAR, Mónica (coord.); VARELA CASTRO, Ignacio (coord.), Mujer, maternidad y derecho, Tirant lo Blanch, Valencia, 2019; 933 págs.
}

\section{DOI: http://dx.doi.org/10.15304/dereito.29.1.6565}

Se trata de una obra colectiva, dirigida por María Paz García Rubio y coordinada por Julia Ammerman Yebra, Mónica García Goldar e Ignacio Varela Castro, que recorre las múltiples repercusiones que la maternidad tiene en el Derecho, sobre todo en el Derecho de familia, aunque también se aportan apuntes desde otras disciplinas. Consta de un prólogo y cuarenta y cuatro estudios distribuidos en cuatro bloques temáticos: maternidad(es) en el siglo XXI; filiación y cambios sociales; maternidad subrogada, y, por último, más allá de la maternidad. La portada, ilustrada con la obra Madre, uno de los cuadros más bellos de Sorolla, nos presenta este libro, sobre un tema tan antiguo y cambiante como la propia vida: la maternidad (como construcción histórica y social compleja).

Abre el primer bloque un estudio de Teresa Castro Martín, aportando el punto de vista de la Demografía sobre la maternidad en el siglo XXI. Desde el propio cuestionamiento de la institución tradicional de la maternidad, a la evolución de las nuevas maternidades, que en ocasiones escapa del estricto ámbito jurídico.

Teodora Torres García rastrea la progresiva adaptación de las normas jurídicas referidas a la filiación de la maternidad, en relación al reconocimiento constitucional de la igualdad entre hombres y mujeres. Cristina Zoco Zabala analiza, desde una perspectiva constitucional, la exigencia de igualdad con el fin de determinar que la desaparición de la exclusividad de la maternidad para las mujeres en el ámbito laboral debe redundar en una modificación que incluya a todos los progenitores con independencia de su identidad sexual.

Sobre el nuevo paradigma de la maternidad y las múltiples formas de ser madre reflexionan Encarnación Serna Meroño y Carmen Sánchez Hernández, desde la forma biológica tradicional, determinada por la gestación y el parto, al denominado "derecho a procrear", disociando entre maternidad genética, biológica, legal y social. Judith Solé Resina muestra el amplio abanico de situaciones que puede originar una relación de filiación, frente a las formas clásicas de tener hijos, a las que las reformas en materia de filiación se muestran insuficientes. Desde la doble maternidad en parejas homosexuales Miguel Gómez Perals estudia las vías para el reconocimiento del vínculo jurídico que existe entre la mujer y el hijo nacido de su pareja femenina, y cómo la legislación ha ido reflejando esta situación.

María Elena Sánchez Jordán reflexiona sobre el tratamiento doctrinal y jurisprudencial de la obligación parental de mantenimiento y derecho de reembolso de la madre sola. Julia Ammerman Yebra y Aurelio Barrio Gallardo ponen de manifiesto la ausencia de la perspectiva de género en el ámbito jurisdiccional, la necesidad de una composición diversa de los máximos órganos jurisdiccionales y de una interpretación de las normas 
desde la doctrina feminista. María José Cazorla González se ocupa de los nuevos retos que suponen para el Derecho la sexualidad y maternidad de la mujer con discapacidad, con el necesario estudio de su consentimiento en el ámbito sanitario, la esterilización forzosa, el aborto coercitivo, el libre desarrollo de su sexualidad o el acceso a la maternidad. Las repercusiones en el ámbito de los riesgos laborales es revisada por María del Carmen Grau Pineda, que propone incorporar el enfoque de género en los aspectos de salud laboral, especialmente en la evaluación y prevención.

De la maternidad también se derivan responsabilidades familiares y de cuidados. Los estudios evidencian un notable desequilibrio en el reparto de las cargas familiares, así como la falta de conciliación de la vida familiar y laboral, pues la paternidad y la maternidad tienen consecuencias distintas en la vida y en la trayectoria profesional de hombres y mujeres. Ana María Pérez Vallejo centra su atención en los indicadores sobre las brechas existentes en torno a la maternidad y las prácticas discriminatorias asociadas a ésta, proponiendo medidas que aumenten la igualdad en materia de oportunidades de empleo y responsabilidades de cuidado para ambos sexos. Del estudio de los principios fundamentales de corresponsabilidad parental y coparentalidad tras el divorcio se ocupa Javier Martínez Calvo.

Los trabajos del segundo bloque se centran en la filiación, por ser uno de los temas que, junto a su constante problemática, ha experimentado mayores cambios. Silvia Tamayo Haya estudia el debate sobre la existencia, contenido y límites del derecho a procrear, en el ámbito de las tecnologías reproductivas desarrolladas en los últimos años, los nuevos tipos de familia y la exigencia de políticas sociales de apoyo familiar.

En el contexto de la autonomía de la voluntad en la determinación de la filiación Marta Ordás Alonso estudia el debate en torno a los derechos que entran en conflicto con el anonimato de la madre, frente a los derechos de la persona a conocer sus orígenes. De la "renuncia" a la maternidad se ocupan María Aránzazu Calzadilla Medina y Ma del Carmen Gete-Alsonso Calera tratando de concretar el sentido con el que aparece el término en la Ley 20/2011, de 21 de julio, de Registro Civil, al referirse a la renuncia de la madre en el momento del parto, cuya parca regulación requiere de una delimitación conceptual que concrete los requisitos y efectos de la misma. Beatriz Verdera Izquierdo analiza la relevancia de la autonomía de la voluntad de la madre en el reconocimiento de complacencia, a pesar de la falta de realidad o veracidad biológica en que pueda desarrollarse. En esta misma línea, Adoración Padial Albás expone como punto de partida si el consentimiento, como medio de determinación de la filiación, es la causa fundamental del ocaso del principio de veracidad biológica o la libre investigación de la paternidad, centrando su estudio en el Código civil de Cataluña. Concepción Rodríguez Marín presenta un estudio sobre la problemática del art. 124 del Código Civil ante un reconocimiento voluntario de la filiación no matrimonial, refiriéndose principalmente a la aplicación e interpretación del precepto respecto a los menores de edad y personas con la capacidad modificada judicialmente. 
Belén Andreu Martínez toma como eje principal el análisis de una sentencia en la que se plantea el recurso a la auto-inseminación por un matrimonio de mujeres, evidenciando problemas para los que no existe en nuestro Derecho una respuesta correcta.

Carolina Mesa Marrero plantea el estudio del resarcimiento del daño moral a propósito de una sentencia que condena a un centro médico a satisfacer una indemnización por los daños y perjuicios que el resultado de la fecundación in vitro ha producido a la demandante y a sus hijos, al utilizar el material reproductivo de otro varón distinto al del que era pareja de la actora. Eshter Farnós Amorós analiza la jurisprudencia y muestra cómo en casos de responsabilidad civil por engaño o incertidumbre sobre la paternidad, los tribunales aplican el derecho de forma estereotipada, perjudicando a las mujeres que se alejan del ideal de "buena madre".

Mónica Sumoy Gete-Alonso acude a la filmografía de Pedro Almodóvar para sistematizar los distintos modelos de maternidades que el cineasta manchego representa, incluso antes de haber sido aceptados o reconocidos desde un punto de vista social, moral o jurídico.

Francisco Oliva Blázquez analiza críticamente el contenido de una sentencia del Tribunal Constitucional sobre objeción de conciencia en la dispensación de la "píldora del día después", frente a la vulneración del derecho a la salud sexual y reproductiva de la mujer. Por último, María Ángeles Catalina Benavente muestra las consecuencias que tiene la pasividad de los progenitores, en un proceso de determinación de la filiación, para los hijos reconocidos, analizando un caso con gran repercusión mediática en la prensa social.

El tercer bloque agrupa once trabajos sobre maternidad subrogada, con las inevitables connotaciones éticas, económicas, políticas y jurídicas que presenta un tema tan controvertido como éste. Reflexionan desde un planteamiento inicial y conceptual, así como sobre las diferentes posturas en torno a su admisibilidad, o su necesaria futura legislación en España, Beatriz Hermida Bellot, Ángel Sánchez Hernández, Ignacio Varela Castro y Santiago Álvarez González, éste último lo hace desde la intrínseca dimensión internacional que presenta el problema. Desde un contexto más amplio, el de la autonomía de la voluntad frente a la imperatividad de las normas en el ámbito del Derecho de familia lo hace Sara Zubero Quintanilla. Natalia Pérez Rivas aborda el tratamiento de la maternidad subrogada, la adopción ilegal y la venta de menores desde su regulación en el Código Penal español. Desde la perspectiva del Derecho comparado, aunque las referencias a la regulación de otros países es constante a lo largo del libro, Inmaculada Espiñeira Soto y María Dolors Toldrá Roca se ocupan de la legislación portuguesa sobre gestación de sustitución en Portugal, y Alberto Escobar Rivas muestra la regulación de la maternidad subrogada en Reino Unido.

Ana Cañizares Laso reflexiona desde el contexto del caso Paradiso y Campanelli, advirtiendo que aunque no deben extraerse conclusiones generales, sí la necesidad de una próxima regulación sobre la gestación por sustitución, que pondere adecuadamente los intereses en juego. Eugenio Pizarro Moreno muestra cómo el proceso de maternidad subrogada, en sí 
mismo, atenta contra la dignidad de la persona a través de un estudio de caso: el de las mal denominadas éticamente "granjas de mujeres".

Por último, el cuarto bloque recoge perspectivas que afectan tanto a la decisión de ser madre, como a las consecuencias de serlo efectivamente, agrupando trabajos más heterogéneos en cuanto a sus temáticas. Arantzazu Vicandi Martínez expone la necesidad de evolucionar la configuración jurídica de las capitulaciones matrimoniales, más allá de la mera regulación económica del matrimonio, hacia pactos que simplifiquen futuras crisis. Neus Cortada Cortijo estudia la función de la compensación económica, por razón de trabajo, en el Derecho civil catalán en el marco del régimen matrimonial de separación de bienes, con el propósito de reconocer la feminización del trabajo doméstico no remunerado, como reto para garantizar el principio de igualdad entre cónyuges. Pilar Domingo Martínez se ocupa del tratamiento de la responsabilidad civil que se deriva de una conducta discriminatoria por razón del sexo, centrándose en la aplicación del principio de igualdad de trato en el contrato de seguro. María José Senent Vidal centra su estudio en el comercio con los cuerpos de las mujeres a través de la prostitución desde una perspectiva global y de género, que pasa por desvelar las nuevas formas de subyugación mediante el denominado "mito de la libre elección". Desde una dimensión más teórica Juan Alfredo Obarrio Moreno parte de la lectura de un clásico de Sófocles, Antígona, para reflexionar sobre la condición ética del ser humano y la determinación sustancial de la mujer en la familia.

Con una mirada a un futuro a corto plazo, Blanca Sillero Crovetto dedica su estudio a la agenda 2030 para el desarrollo sostenible, que señala como esferas de importancia para la humanidad: las personas, el planeta, la prosperidad, la paz y las alianzas. La agenda pone en el centro la dignidad y la igualdad de las personas y requiere de la participación de todos los sectores de la sociedad y del Estado para su implementación.

En definitiva, la obra responde a un esfuerzo necesario para abordar el estudio de los nuevos aspectos jurídicos de la maternidad. Y se convierte en un libro de referencia para quienes se dispongan a pensar críticamente sobre los problemas de las madres, sobre las respuestas que el Derecho da a esos problemas, y sobre si esas respuestas nos hace libres e iguales.

Celia Prados García Profesora Ayudante Doctora Universidad de Córdoba cprados@uco.es 